\title{
Dispersal of Potato Cyst Nematodes Measured Using Historical and Spatial Statistical Analyses
}

\author{
N. C. Banks, M. Hodda, S. K. Singh, and E. M. Matveeva
}

First and second authors: CSIRO Ecosystem Sciences, GPO Box 1700, Canberra, ACT 2601, Australia; third author: CSIRO Ecosystem Sciences, GPO Box 1700, Canberra, ACT 2601, Australia and Cooperative Research Centre for National Plant Biosecurity, Bruce, ACT 2617, Australia; fourth author: Institute of Biology of Karelian Research Centre, Russian Academy of Sciences, Pushkinskaya st. 11, 185910 Petrozavodsk, Republic of Karelia, Russia.

Accepted for publication 15 December 2011.

\begin{abstract}
Banks, N. C., Hodda, M., Singh, S. K., and Matveeva, E. M. 2012. Dispersal of potato cyst nematodes measured using historical and spatial statistical analyses. Phytopathology 102:620-626.

Rates and modes of dispersal of potato cyst nematodes (PCNs) were investigated. Analysis of records from eight countries suggested that PCNs spread a mean distance of $5.3 \mathrm{~km} /$ year radially from the site of first detection, and spread $212 \mathrm{~km}$ over $\approx 40$ years before detection. Data from four countries with more detailed histories of invasion were analyzed further, using distance from first detection, distance from previous detection, distance from nearest detection, straight line distance, and road

$\mathrm{km} / \mathrm{year}$, and did not differ statistically between countries. Time between the first detection and estimated introduction date varied between 0 and 20 years, and differed among countries. Road distances from nearest and first detection were statistically significantly related to time, and gave slightly higher estimates for rate of spread of 6.0 and $7.9 \mathrm{~km} / \mathrm{year}$, respectively. These results indicate that the original site of introduction of PCNs may act as a source for subsequent spread and that this may occur at a relatively constant rate over time regardless of whether this distance is measured by road or by a straight line. The implications of this constant radial rate of dispersal for biosecurity and pest management are discussed, along with the effects of control strategies.
\end{abstract} distance. Linear distance from first detection was significantly related to the time since the first detection. Estimated rate of spread was 5.7

The potato cyst nematodes (PCNs) Globodera rostochiensis and G. pallida are two highly specialized plant-parasitic nematodes that are serious pests of solanaceous plants; most importantly, the potato. PCNs originated in the Andes region of South America. They spread throughout Europe with the introduction of new varieties of potato in mid 19th century and, from there, to 72 countries worldwide (6). PCNs are capable of causing severe crop damage, with $100 \%$ yield loss at high abundances (5), and can be very costly to manage $(13,28)$. Thus, they pose a significant threat to the global potato industry (5). Once established, eradication of PCNs is difficult because of their long term survival (20 to 30 years) as cysts in the soil without a suitable host (49), the difficulty of detection at early stages of infestation (2), sporadic detections some distance from known locations (27), and differential virulence of the many pathotypes to resistant potato cultivars (39). Because eradication is so difficult, management practices such as surveillance and quarantine are widely implemented to prevent spread of PCNs in countries and potato-growing areas where they are not widespread (22). Hygiene measures have also been put in place to prevent spread within countries where PCNs are established, resulting in containment (12).

Therefore, an understanding of dispersal is essential to manage PCNs. In turn, data for PCNs can be used to improve models of dispersal for other pests of quarantine and biosecurity significance, which, despite many advances, still contain many uncertainties and areas requiring further research (37).

Corresponding author: M. Hodda; E-mail address: mike.hodda @ csiro.au

*The $\boldsymbol{e}$-Xtra logo stands for "electronic extra" and indicates that the online version contains two supplementary tables.

http://dx.doi.org/10.1094/PHYTO-08-11-0224

(c) 2012 The American Phytopathological Society
Additional keywords: Globodera rostochiensis, G. pallida, invasive.

Rates of spread among potentially invasive species have been extensively researched over several decades $(15,17,21,44)$. The simplest models were based on parameters such as the population growth rate and movement of individual organisms $(34,45)$. However, empirical studies found that these models did not always predict rates of spread accurately due to rare long-distance dispersal events skewing the statistical distribution of the real data $(1,11,24)$. Despite the challenge these long-distance jump events pose to modeling dispersal $(14,17)$, there are few studies and limited data available on the generality of such dispersal mechanisms.

For invasive species closely associated with humans, such as the Argentine ant (Linepithema humile), human-mediated longdistance jump dispersal can be the main influence on spread because dispersal at the largest (continental) scales has been driven by human commerce but becomes less important at smaller (regional and local) scales. Therefore, natural dispersal is relatively unimportant at the largest scales but becomes increasingly important at smaller scales (48). Dispersal of a number of other invasive species has also been found to follow this pattern $(36,42)$. Suarez et al. $(48)$ suggested that both human and natural dispersal mechanisms play a role in spread at the regional scale. Jump dispersal at this scale was measured in two ways. One was the distance of each new introduction from the original site of infestation. This method assumed that the original locality was the source of each new detection and measured the maximum distance of jumps. The other was the distance of each new introduction from the nearest occupied locality. This method assumed that each new incursion emanated from the nearest occupied territory, and measured the minimum distance of jumps.

Following a similar methodology, this article reports investigations into the rate of spread of PCNs in different countries using three methods of measurement, corresponding to the as- 
sumptions that (i) every new detection of a $\mathrm{PCN}$ originates from the nearest occupied locality, (ii) the source of each new PCN detection is the previous locality in which it was found, and (iii) the original site of introduction of a PCN acts as the source for all subsequent spread (perhaps related to being the oldest and largest population). Measurements of distances in a straight line and along roads were also compared. The inferences which can be drawn about rates and modes of dispersal from this data are discussed.

\section{MATERIALS AND METHODS}

Dates and localities of PCN detections globally were collated from published and unpublished official records $(4,10,16$, $28,38,41,50$ ) (E. M. Matveeva, unpublished). Only data from commercial potato fields were used (with the exception of New Zealand). Eight countries had at least two data points available: a locality and date of first detection and a locality and date of the recent detection farthest from the first detection (Supplementary Table 1). These were plotted on maps of each country in Google Earth and straight-line distances between the points were calculated using the ruler line tool. Most jumps were $<800 \mathrm{~km}$ but a few jumps were over very long distances of $>2,000 \mathrm{~km}$. These involved transoceanic or cross-country dispersal across major barriers (open sea or desert), and were almost certainly associated with human activity on the largest spatial scale; therefore, they were excluded from analyses. This was data set 1 .

For four countries, complete, well-documented invasion histories were available $(4,10,38)$ (E. M. Matveeva, unpublished) (Supplementary Table 2). These data were also plotted on country maps in Google Earth but rates of spread were estimated in three ways: first, by using the straight-line distance between each new incursion and the nearest site of occupation (nearest locality); second, by using the straight-line distance between each new incursion and the previous one (previous locality); and third, by measuring the straight-line distance of each new incursion from the original site of invasion (origin). The maximum and minimum distance by road between detections was also calculated for each of the models using the ruler path tool. This was data set 2 .

Invasions identified as a particular species or pathotype were considered separately from any subsequent detection of the other species of PCN or pathotype. Where the initial identification was either a mixed population or predated recognition of G. pallida as a separate species, all subsequent records were treated as part of one invasion.

All data were analyzed using regression models using GenStat (13th edition) (53). The residuals and fitted values were checked for evidence of heteroscedasticity and multicollinearity, and appropriate transformations applied if necessary to fulfill the assumptions of the analyses (54).

\section{RESULTS}

Data set 1. Spread of PCNs covered 82 to $702 \mathrm{~km}$ over 4 to 55 years (Fig. 1). The line of best fit suggested a mean rate of spread of $5.3 \mathrm{~km} /$ year from the site of first detection and a spread of $218 \mathrm{~km}$ before detection; however this line was not statistically significant (Table 1) $\left(\% R^{2}=36 ; \mathrm{df}=2,6 ; P=0.11\right)$.

Data set 2. Most distances between detections were $<100 \mathrm{~km}$, and results were similar for straight-line and road distances (Table 1). The size of jumps from both nearest and previous localities were statistically unrelated to time since the nearest or previous record or the date PCNs were first recorded in the country (Table 1).

For distance from the origin, the size of jumps was related to time since introduction and the country (Table 1; Fig. 2). The rate of spread (slope of the lines) was $5.7 \mathrm{~km} /$ year, and was not significantly different for the different countries $(F=1.60$, df $=$ $3.28, P=0.21$; because data were analyzed using stepwise linear regression, all slopes were the same). The intercepts of the regression lines with the $\mathrm{x}$-axis represent the year when PNC were only at the origin, or the date of introduction. These intercepts were

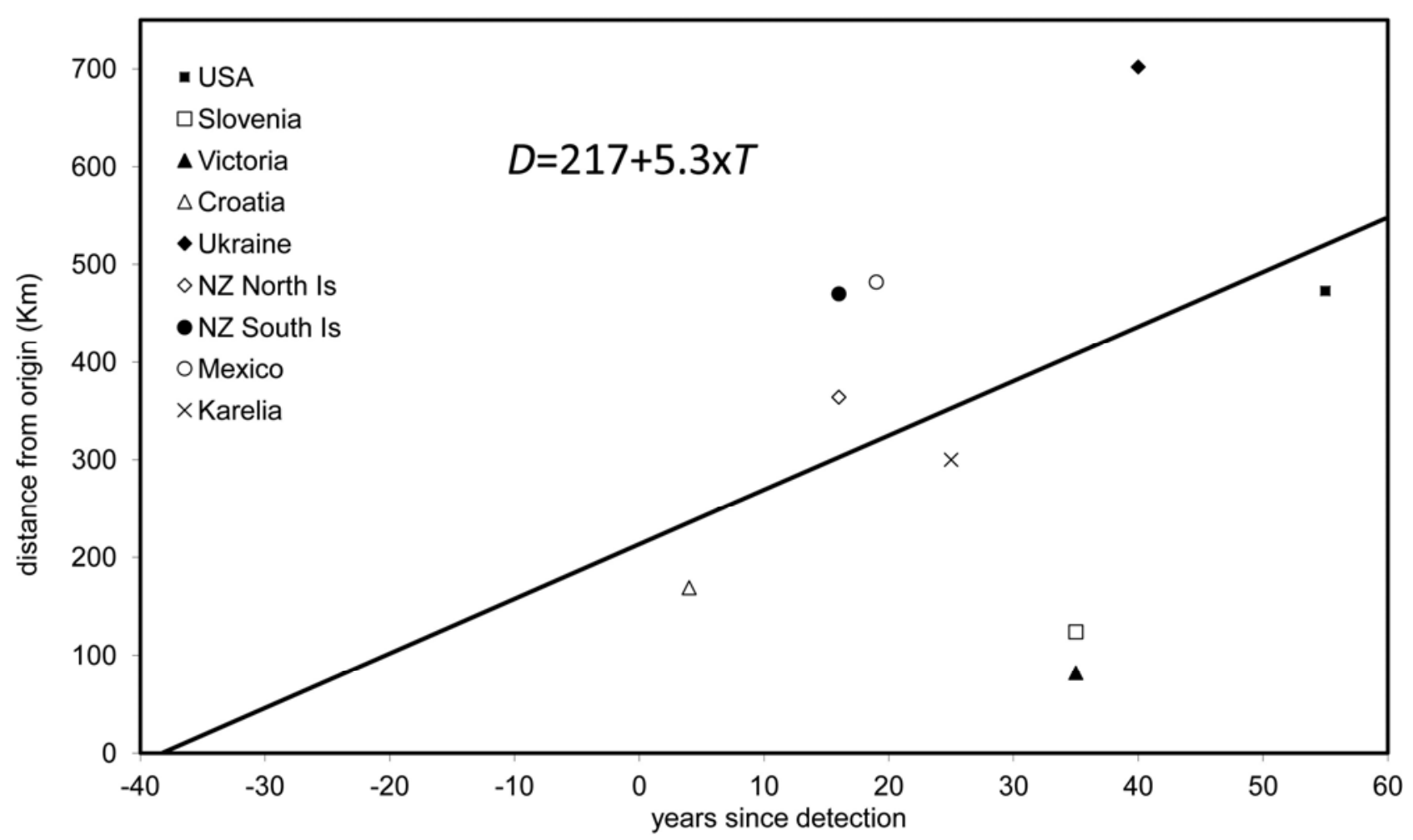

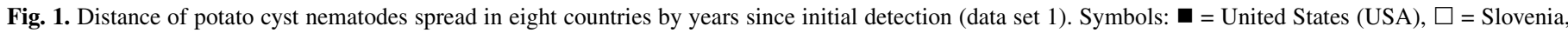

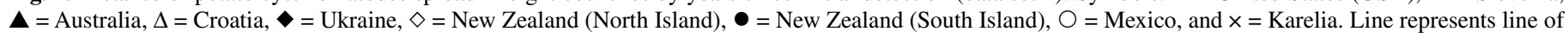
best fit (see Results, data set 1). 
different for the different countries (Table 1; Fig. 2). The intercepts for Australia and Karelia were not significantly different from zero $(t=0.04, \mathrm{df}=31, P=0.99$ and $t=0.53$, df $=31$, $P=0.601$, respectively), whereas those for Slovenia and the United States were different from zero $(t=2.54$, df $=31$, $P=0.017$ and $t=2.27$, df $=31, P=0.030$, respectively). Road distances from the origin were also related to time since introduction and country but with less statistical significance (Table 1). The rates of spread (slope) of the road data were 6.0 and $7.9 \mathrm{~km} /$ year for the nearest locality and origin methods, respectively.

\section{DISCUSSION}

Data sets. Data set 1 showed no statistically significant trends. There are many features of the data that may explain such a result, and they are discussed below. However, the line of best fit produces a remarkably similar estimate for the mean annual spread of PCNs $(5.3 \mathrm{~km} / \mathrm{year})$ to that of the more detailed data set $2(5.7 \mathrm{~km} /$ year $)$. Interestingly, both of these estimates are similar to the median radial expansion rate of non-native terrestrial invertebrates in the United Kingdom (52), which could suggest similar means of dispersal.

TABLE 1. Statistical summary of analysis of records of potato cyst nematodes spread over time

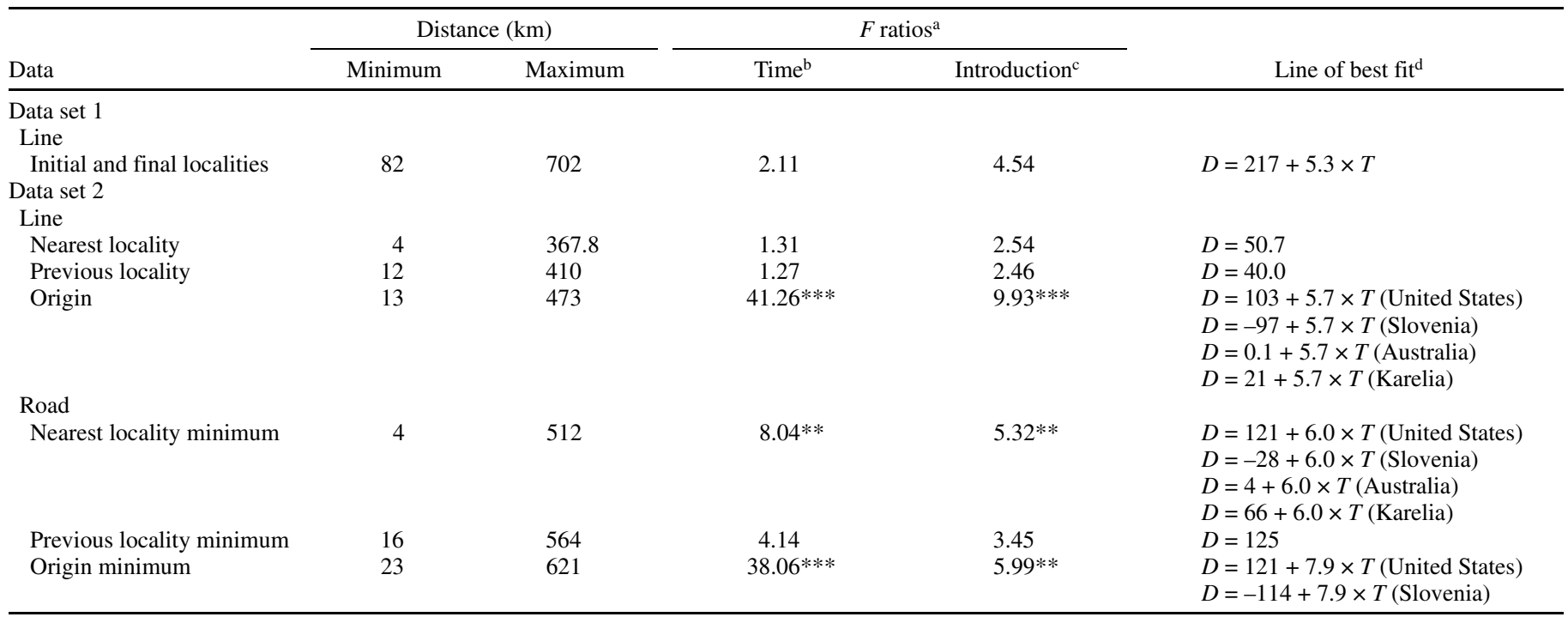

a Asterisks show statistical significance: *,**, and *** indicate $P(\mathrm{Ho})<0.05,0.01$, and 0.001 , respectively.

b Slope or time coefficient term.

${ }^{\mathrm{c}}$ Initial introduction (intercept or constant term).

d $D=$ distance in kilometers and $T=$ time in years since first detection $(t$ test results in text).

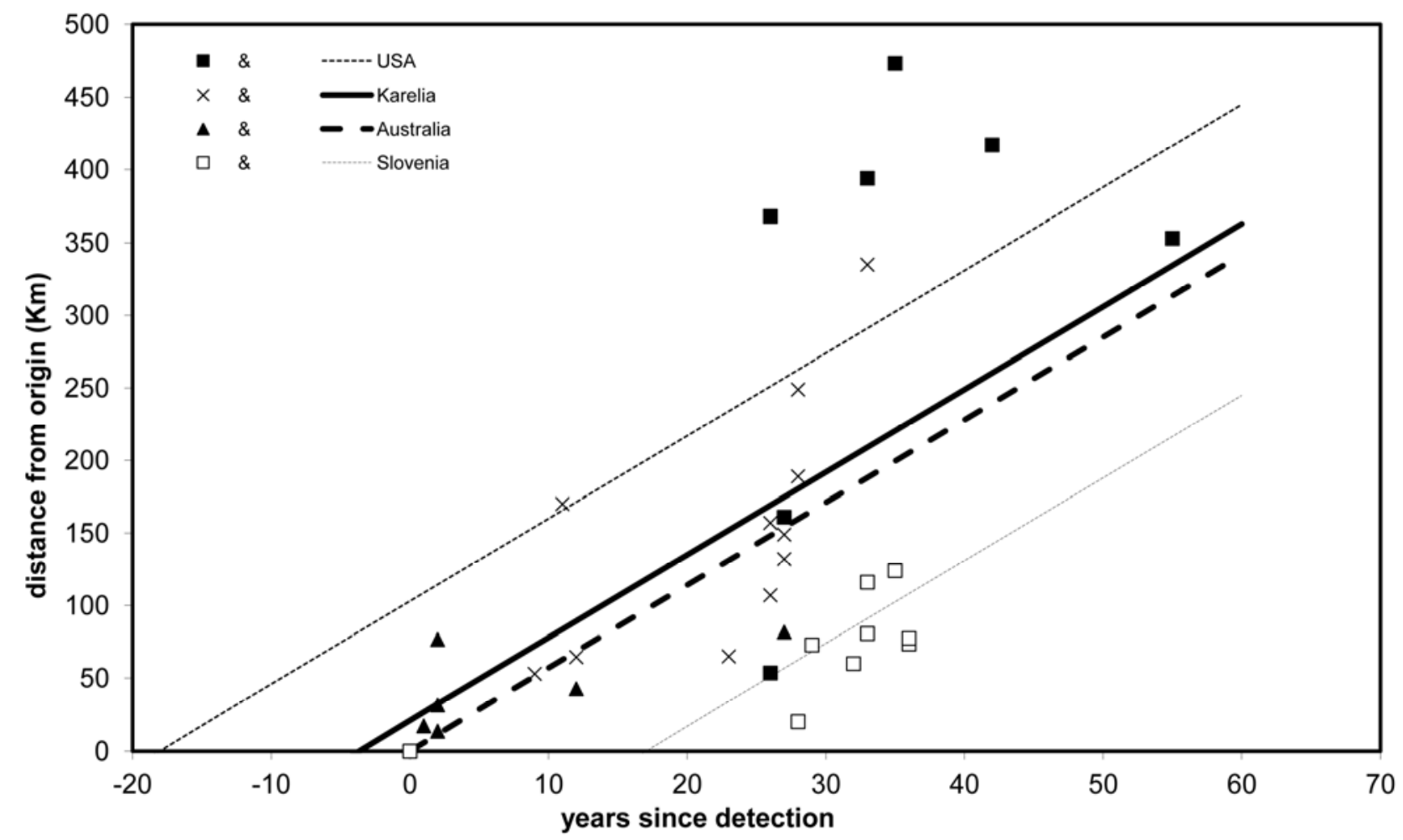

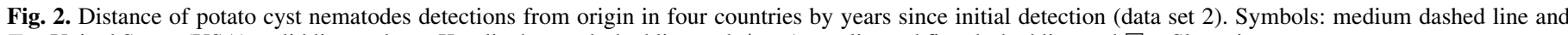
$\mathbf{\square}=$ United States (USA), solid line and $\times=$ Karelia, heavy dashed line and $\boldsymbol{\Delta}=$ Australia, and fine dashed line and $\square=$ Slovenia 
Analysis of data set 2 showed that the estimate of spread from the origin model $(\approx 5.7 \mathrm{~km} /$ year $)$ had the strongest statistical support and considerable robustness to different assumptions about dispersal mechanisms and methods of calculating spread. The estimated rates of spread for the road data $(6.0 \mathrm{~km} /$ year from the nearest potential source and $7.9 \mathrm{~km} /$ year from the original detection) are entirely consistent with the slightly lower straightline distances.

The analysis of jumps from the previous locality showed no dependence on time: that is, a mean jump of 40 or $50 \mathrm{~km}$ (Table 1). With a mean time between jumps of just $<8$ years, these models of spread imply a mean annual rate of 5.0 to $6.3 \mathrm{~km} /$ year. If these jumps were in random directions, as they appear to be from the data, then this suggests radial expansion of the infested area of 4.1 to $5.1 \mathrm{~km} /$ year (based on simulation models) (M. Hodda, unpublished).

Overall, there is relatively close agreement of estimates given the range of data sources as well as the various models of dispersal and measurements of spread.

Distribution of PCNs in the landscape. PCN invasions are characterized at the regional scale by a patchy distribution (27), and rates of spread at this scale may be indicative of the amount of invasible land available. Some invasive species colonize available areas faster at smaller (local) scales and at a slower rate on larger (regional) scales due to fragmentation of suitable habitat (potato fields) within less suitable areas (such as scrubland). The fragmented landscape acts as a semipermeable barrier and slows the spread of the invasive organism $(17,24)$. The data do not appear to show that landscape patterns have much effect on invasion by PCNs, with similar rates observed everywhere, perhaps indicating a common dispersal mechanism.

Mechanisms of dispersal. Movement and dispersal of PCNs may be by humans or natural processes. The present analyses do not definitively separate the different dispersal mechanisms but they do suggest what may be happening.
The results of the nearest and previous locality models imply random jumps of distances of $\approx 40$ to $50 \mathrm{~km}$. The distance of jumps was statistically independent of the time PCNs have been present, and seem likely to represent human-assisted spread. The chief forms of spread of PCNs over long distances by humans are by movement of contaminated soil adhering to tubers, equipment, and machinery as well as to the roots or bulbs of plants grown in contaminated fields $(26,46)$. Uncontrolled or inadequate control of this movement may have resulted in spread over considerable distances.

The patterns observed within data set 2 may support this explanation and demonstrate the power of the present analyses in measuring the effect of changes in control regimes. A new control regime was implemented in 1976 in the United States, and there was subsequently a decrease in the size of jumps (Fig. 3). Prior to 1972, attempts to control PCNs consisted of chemical fumigation and were often followed by the continuation of potato production using susceptible cultivars and crop rotation. Regulations on the movement and sanitization of plants, equipment, and machinery from potentially contaminated fields were also put in place $(5,9,46)$. From 1972 onward, integrated systems involving fumigation, resistant cultivars, and crop rotation were established to reduce PCN populations to below detectable levels in order to minimize the risk of spread. Control practices similar to the post1972 strategies in the United States and which include the 1968 regulations have been adopted by other countries, including Australia and Slovenia (which, like the United States, only had pathotype Ro1). These practices were coupled with stringent quarantine methods such as longer crop rotations, prohibition of potato growing in heavily infested areas for a minimum of 10 years, and implementation of buffer zones around known infested areas to limit the availability of hosts and, thus, prevent further spread $(28,38)$.

These observations lend weight to the hypothesis that humanassisted dispersal is more important in the spread of PCNs at the

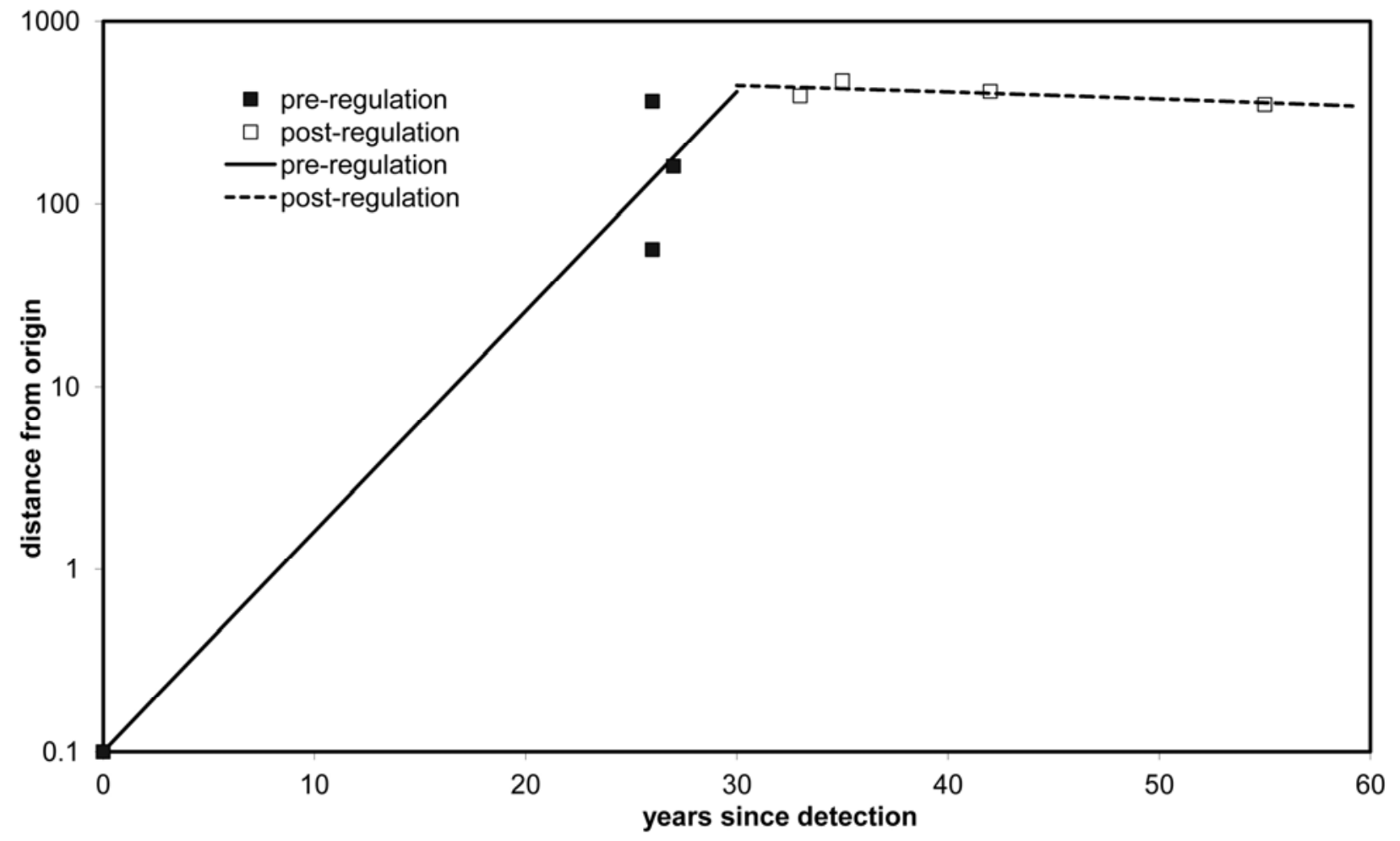

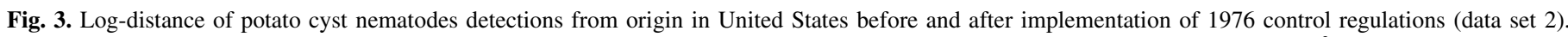

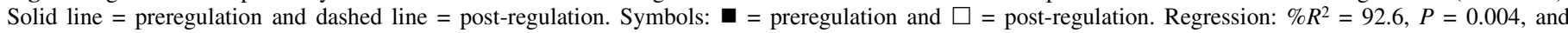

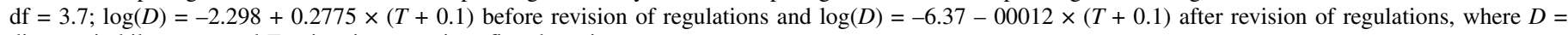
distance in kilometers and $T=$ time in years since first detection. 
regional scale because most jump distances are $>10 \mathrm{~km}$ and all measures of natural dispersal mechanisms for PCNs are considerably less than this.

For example, the natural movement of nematodes through the soil has been calculated as 1 to $2 \mathrm{~m}$ per year (19), a figure too small to account for anything but local spread. Water, wind, animals, and plants may also assist dispersal. Movement via irrigation, run-off, or flood water may be a factor in the spread of nematodes $(7,8,25,32,51)$. Sand storms could spread nematode cysts long distances (35); dust storms are known in the United States and Australia. Chitwood (9) found that wind had the capacity to blow dust containing viable cysts $0.3 \mathrm{~km}$ (935 feet) from an infected field. The number of viable PCN cysts, although small, could potentially form an invasive population: 1 cyst per gram of soil has the capacity to generate 30 cysts by the end of a single growing season (20). Other nematodes are known to be moved by animal vectors such as insects and birds $(3,25,43)$. Morgan (33) investigated the potential for farm animals and wildlife to act as vectors for PCNs in Newfoundland, Canada. His initial experiments found that viable cysts could be passed by animals with single stomachs but not by ruminants and birds. Another possibility is natural dispersal on alternative plant hosts because their movements are less regulated than those of potato.

In summary, natural dispersal mechanisms may play a role in the spread of PCNs but only at a local scale because the distances suggested are too small to account for the size of jumps displayed in the data. Our analyses do not definitively prove that humanassisted spread is the primary dispersal mechanism of PCN, because the measures are indirect and other factors such as survey intensity and monitoring also play a role. However, they do suggest that human factors are important. Definitive proof of the roles of all these different factors may be determined only from direct measurements.

Influences on observed dispersal rates. There are a number of features of the data that affect their interpretation and the actual or measured rates of dispersal obtained from the data.

First, the initial detection of PCNs in a country is not necessarily the date it arrived, merely the first time the organisms were found and recorded. Poor detection is a major issue with PCNs $(2,13,27)$, and is likely to have a larger effect on initial records, especially earlier in time when the threat of PCNs was less recognized than today $(26,27)$. In addition, long potato crop rotations may mean that $\mathrm{PCN}$ populations remain below detectable levels for long periods, and sampling intensity and management may also affect the dispersal distance. Considerable inaccuracy in the dates of initial detections may be the reason that the records in data set 1 show no statistical relationship between distance travelled and time since introduction. The line of best fit in data set 1 suggests that actual introduction may have been up to $\approx 40$ years before the first detection (Table 1 ).

Data set 2 may give further insight into this phenomenon.

In data set 2, Australia and Karelia intercepts were close to and not significantly different from zero (Table 1). This suggests detection close to the initial infestation. The United States and Slovenia had non-zero intercepts that were statistically different from zero. This suggests that the infestations of PCN were not found at the initial seeding date in each of these countries. The trend line for the Slovenian data set was unusual and may indicate that a PCN was detected while population numbers were below normally detectable levels; a "lucky strike". In the United States, the trend lines calculated with detailed invasion data give an indication of the possible dates of introduction of PCNs 21 years before detection (Fig 2). Historical data lend weight to this estimate. Plant damage in the original potato field in Nassau County was first noticed in 1934 and G. rostochiensis was positively identified as the cause of this damage in 1941 (5). The nematode was thought to have been introduced into the area on contaminated military equipment returning from WWI (46) and the original infested field was part of a temporary military encampment (5). A seeding date in the early 1920s was inferred (5). The trend line in the present study estimates the seeding date as 1920 (Fig. 2). This example demonstrates the utility of these analyses in estimating potential initial infestation dates for PCN where detailed historical data are available.

The various statistical models of spread mostly show remarkable uniformity in the estimates of rate of spread per year but they show considerable differences in the dates of first detection relative to the date of first infestation. This implies that detection is important and that failing to account for a latent period, when an infestation is present but undetected, may lead to very different interpretations of invasion data.

These estimates also have implications for surveillance strategies and exclusion zones. If the estimates of the potential invasion area of PCNs (calculated by multiplying rate of spread by number of years since initial introduction) are greater than current estimates project, then survey areas may need to be expanded accordingly. Additionally, the restricted areas for seed potato production around exclusion zones may also need to be expanded and strictly enforced if PCNs are travelling at a constant rate per year. The dispersal of PCNs actually may be further than is commonly recognized, a feature of other invasive nematodes such as pine wood nematode (Bursaphelenchus xylophilus), and this may influence the best responses to incursions (18). Again, direct investigation is needed to confirm our estimates.

A second feature affecting interpretation of results is that detection points are approximate. Exact geographical coordinates of fields where PCNs have been found are not generally available because of privacy concerns; data points are limited to towns, regions, or counties. Because many jumps were $>20 \mathrm{~km}$, distances between fields of even a few kilometers would have little effect on the data.

A third feature is that, due to the historical nature of the data, the two species of PCNs were not always distinguished G. pallida was only recognized as a separate, distinct species in 1973 (47). Recognition that the two species often exist in mixed populations was recognized as widespread even later $(29,30)$. In the present study, when an invasion was identified as a particular species or pathotype, subsequent detection of the other species was considered to be separate. Where the initial identification was either mixed or predated recognition of $G$. pallida, all subsequent records were treated together, because the two species commonly occur together $(28,29)$.

A fourth feature affecting interpretation is that points represent detections, not necessarily persistence of PCNs in an area. The aim of the present investigations was to determine rates of spread; therefore, persistence of PCNs in any given locality is not of consequence other than for its effect on probability of detection.

A fifth feature affecting interpretation of results is that dispersal was treated simplistically as being from nearest, previous, or original locations. Analyses of dispersal of a range of organisms have suggested that seldom is dispersal simply related to only one of these source locations $(31,40)$. Often, dispersal is not simply from the nearest inhabited site $(23,31)$. However, the relative importance of the various sources of dispersing organisms can be very different and have a great influence on the overall rate and pattern of spread (23). Hence, the present result that the original location seems to act as the predominant source for dispersal is important.

Method of analysis. The results of this study show that analyses of spread of invasive organisms using regression techniques that include one or more intercept terms can be useful in revealing patterns within data. Simple calculations of ratios of distances divided by time since first detection do not take into account the period when the organism may be present yet undetected. If these periods are included by the inclusion of intercept terms in analyses of detection data, then similarities in 
dispersal rates as well as dates of initial invasion that would otherwise be hidden may emerge.

Another point to emphasize is the considerable power now available in using global location systems to plot the dispersal of invasive organisms. Although availability of data is still crucial, once available, detection data can be used in many ways relatively easily; for example, to monitor or predict spread or to measure the effects of changes in containment.

Conclusion. This study suggests that PCN dispersal may be modeled using a series of infrequent random jumps of 40 to $50 \mathrm{~km}$ or as a radial spread from the first detection of $\approx 5.7 \mathrm{~km} /$ year (origin model), with minimal difference between straight-line or road measurements. The first detection may differ considerably from date of first arrival inferred from the statistical models applied. Human agency may be a more important factor than natural processes in the spread of PCNs at the regional scale. There are still many aspects of dispersal of $\mathrm{PCNs}$ requiring investigation, including detection at low abundances early in the invasion process and the role of alternative hosts. Spatial and historical data analyses are useful in suggesting overall trends and, with some assumptions, can estimate initial PCN infestation dates. These, when combined with the estimates of radial spread, can help estimate appropriate sizes of surveillance areas and exclusion zones for PCNs.

\section{ACKNOWLEDGMENTS}

We thank the staff at CSIRO Black Mountain Library for the timely supply of less accessible articles; and S. Bond (Centre for Resource and Environmental Studies, Australian National University), D. Paini, D. Kriticos (CSIRO Ecosystem Sciences), and two anonymous reviewers for their valuable comments on the manuscript.

\section{LITERATURE CITED}

1. Allen, L. J. S., Allen, E. J., Kunst, C. R. G., and Sosebee, R. E. 191 . A diffusion model for dispersal of Opuntia imbricata (cholla) on rangeland. J. Ecol. 79:1123-1135.

2. Been, T. H., and Shomaker, C. H. 1996. A new sampling method for the detection of low population densities of potato cyst nematodes (Globodera pallida and G. rostochiensis). Crop Prot. 15:375-382.

3. Brodie, B. B. 1976. Effects of birds ingesting Heterodera rostochiensis cysts on viability of eggs and larvae. J. Nematol. 8:318-322.

4. Brodie, B. B. 1998. Potato cyst nematodes (Globodera species) in Central and North America. Pages 317-331 in: Potato Cyst Nematodes: Biology, Distribution and Control. R. J. Marks and B. B. Brodie, eds. CAB International, Wallingford, UK.

5. Brodie, B. B., and Mai, W. F. 1989. Control of the golden nematode in the United States. Annu. Rev. Phytopathol. 27:443-461.

6. CABI. 2011. Crop Protection Compendium. CAB International, Wallingford, UK.

7. Cadet, P., and Albergel, J. 1999. Passive transport of phytoparasitic nematodes by runoff water in the Sudano-Sahelian climatic area. J. Hydrol. 214:91-102.

8. Cadet, P., Planchon, O., Esteves, M., and Lapetite, J.-M. 2002. Experimental study of the selective transport of nematodes by runoff water in the Sudano-Sahelian area. Appl. Soil Ecol. 19:223-236.

9. Chitwood, B. G. 1951. The golden nematode of potatoes. U.S. Dep. Agric. Circ. No. 875. Washington, DC.

10. Department of Primary Industries, Victoria, Australia 2011. Potato cyst nematode. Online publication.

11. Dwyer, G., Elkinton, J. S., and Hajek, A. E. 1998. Spatial scale and the spread of a fungal pathogen of Gypsy Moth. Am. Nat.152:485-494.

12. European Union. 2007. Council Directive 2007/33/EC of 11 June 2007 on the control of potato cyst nematodes and repealing Directive 69/465/EEC. Off. J. Eur. Union L156:12-22.

13. Evans, K., and Haydock, P. P. J. 2000. Potato cyst nematode managementpresent and future. Asp. Appl. Biol. 59, 91-98.

14. Fagan, W. F., Lewis, M. A., Neubert, M. G., and van den Driessche, P. 2002. Invasion theory and biological control. Ecol. Lett. 5:148-157.

15. Gilbert, M., Grégoire, J.-C., Freise, J. F., and Heitland, W. 2004. Longdistance dispersal and human population density allow prediction of invasive patterns in horse chestnut leafminer Cameraria ohridella. J. Anim. Ecol. 73:459-468.
16. Grubišić, D., Oštrec, L., Gotlin Culjak, T., and Blümel, S. 2007. The occurrence and distribution of potato cyst nematodes in Croatia. J. Pest Sci. 80:21-27.

17. Hastings, A., Cuddington, K., Davies, K. F., Dugaw, C. J., Elmendorf, S., Freestone, A., Harrison, S., Holland, M., Lambrinos, J., Malvadkar, U., Melbourne, B. A., Moore, K., Taylor, C., and Thomson, D. 2005. The spatial spread of invasions: New developments in theory and evidence. Ecol. Lett. 8:91-101.

18. Hodda, M., Smith, D. I., Smith, I. W., Nambiar, L., and Pascoe, I. 2008. Incursion management in the face of multiple uncertainties: A case study of an unidentified nematode associated with dying pines. Pages 15-40 in: Pine Wilt Disease: A Worldwide Threat to Forest Ecosystems. M. Mota and P. Viera, eds. Springer-Verlag, Berlin.

19. Hunt, H. W., Wall, D. H., Decrappeo, N. M., and Brenner, J. S. 2001. A model for nematode locomotion in soil. Nematology 3:705-716.

20. Jones, F. G. W. 1972. Management of nematode populations in Great Britain. Pages 81-107 in: Proc. Annu. Tall Timbers Conf. Tall Timber Research Station, Tallahassee, FL.

21. Jongejans, E., Skarpass, O., and Shea, K. 2008. Dispersal, demography and spatial population models for conservation and control management. Perspect. Plant Ecol. 9:153-170.

22. Lehman, P. F. 2004. Cost-benefits of nematode management through regulatory programs. Pages 1133-1177 in: Nematology: Advances and Perspectives, Vol 2: Nematode Management and Utilization. S. Y. Chen and D. W. Dickson, eds. CAB International, Wallingford, UK.

23. Lindtrom, T., Hakansson, N., and Wennergren, U. 2011. The shape of the spatial kernel and its implications for biological invasions in patchy environments. Proc. R. Soc. Lond. Ser. B 278:1564-1571.

24. Lonsdale, W. M. 1993. Rates of spread of an invading species- Mimosa pigra in Northern Australia. J. Ecol. 81:513-521.

25. Luc, M., Sikora, R. A., and Bridge, J. 1990. Plant Parasitic Nematodes in Subtropical and Tropical Agriculture. CAB International, Wallingford, UK.

26. Mai, W. F. 1977. Worldwide distribution of potato-cyst nematodes and their importance in crop production. J. Nematol. 9:30-34.

27. Marks, R. J., and Brodie, B. B. 1998. Potato Cyst Nematodes: Biology, Distribution and Control. CAB International, Wallingford, UK.

28. Marshall, J. W. 1998. Potato cyst nematodes (Globodera species) in New Zealand and Australia. Pages 353-394 in: Potato Cyst Nematodes: Biology, Distribution and Control. R. J. Marks and B. B. Brodie, eds. CAB International, Wallingford, UK.

29. Minnis, S. T., Haydock, P. P. J., Ibrahim, S. K., Grove, I. G., Evans, K., and Russell, M. D. 2000. The occurrence and distribution of potato cyst nematodes in England and Wales. Asp. Appl. Biol. 59:1-9.

30. Minnis, S. T., Haydock, P. P. J., Ibrahim, S. K., Grove, I. G., Evans, K., and Russell, M. D. 2002. Potato cyst nematodes in England and Walesoccurrence and distribution. Ann. Appl. Biol.140:187-195.

31. Moilanen, A., and Nieminen, M. 2002 Simple connectivity measures in spatial ecology. Ecology 83:1131-1145.

32. Monfort, W. S., Kirkpatrick ,T. L., and Mauromoustakos, A. 2008. Spread of Rotylenchulus reniformis in an Arkansas cotton field over a four-Year period. J. Nematol. 40:161-166.

33. Morgan, G. T. 1968. An informal resume of the Heterodera rostochiensis problem in Newfoundland, and research approaches. In: Proc. Northwestern Nematology Workshop, Vancouver. Burnaby, BC, Canada.

34. Okubo, A. 1980. Diffusion and Ecological Problems: Mathematical Models. Springer-Verlag, Berlin.

35. Orr, C. C., and Newton, O. H. 1971. Distribution of nematodes by wind. Plant Dis. Rep. 55:61-63.

36. Pauchard, A and Shea, K. 2006. Integrating the study of non-native plant invasions across spatial scales. Biol. Invas. 8:399-413.

37. Pitt, J. P. W., Kriticos, D. J., and Dodd, M. B. 2011. Temporal limits to simulating the future spread pattern of invasive species: Buddleja davidii in Europe and New Zealand. Ecol. Model. 222:1880-1887.

38. Potočnik, A., Cvelbar, J. J., Urek, G., and Širca, S. 2008. Potato cyst nematodes situation in Slovenia. In: European Phytosanitary Conference on Potato and Other Arable Crops, Chernovtsy, Ukraine.

39. Powers, T. O., and Fleming, C. C. 1998. Biochemical and molecular characterization. Pages 355-380 in: Physiology and Biochemistry of FreeLiving and Plant-Parasitic Nematodes. R. N. Perry and D. J. Wright, eds. CAB International, Wallingford, UK.

40. Prugh, L. R. 2009. An evaluation of patch connectivity measures. Ecol. Appl. 19:1300-1320.

41. Pylypenko, L. A., Uehara, T., Phillips, M. S., Sigareva, D. D., and Blok, V. C. 2005. Identification of Globodera rostocheinsis and G. pallida in the Ukraine by PCR. Eur. J. Plant Pathol. 111:39-46.

42. Pyŝek, P., Jaroŝik, V., Müllerová Pergl, J., and Wild, J. 2008. Comparing the rate of invasion by Heracleum mantegazzianum at continental, regional, and local scales. Divers. Distrib. 14:355-363.

43. Robinet, C., Roques, A., Pan, H., Fang, G., Ye, J., Zhang, Y., and Sun, J. 2009. Role of human-mediated dispersal in the spread of the pinewood 
nematode in China. PLoS ONE 4(2):e4646. doi:10.1371/journal. pone.0004646.

44. Shigesada, N., Kohkichi, K., and Takeda, Y. 1995. Modeling stratified diffusion in biological invasions. Am. Nat. 146:229-251.

45. Skellam, J. G. 1951. Random dispersal in theoretical populations. Biometrika 38:196-218.

46. Spears, J. F. 1968. The golden nematode handbook: Survey, laboratory, control and quarantine procedures. U. S. Dep. Agric. Agric. Res. Serv. Agric. Handb. No. 353. U.S. Government Printing Office, Washington DC.

47. Stone, A. R. 1973. Heterodera pallida n. sp. (Nematoda: Heteroderidae), a second species of potato cyst nematode. Nematologica 18:591-606.

48. Suarez, A. V., Holway, D. A., and Vase, T. J. 2001. Patterns of spread in biological invasions dominated by long distance jump dispersal: Insights from Argentine ants. Proc. Natl. Acad. Sci. USA 98:1095-1100.

49. Turner, S. J. 1996. Population decline of potato cyst nematodes (Globo- dera rostochiensis, G. pallida) in field soils in Northern Ireland. Ann. Appl. Biol. 129:315-322.

50. Urek, G., Širca, S., Geric Stare, B., Dolničar, P., and Strajnar, P. 2008. The influence of potato cyst nematode G. rostochiensis infestation on different potato cultivars . J. Cent. Eur. Agric. 9:71-76.

51. Villenave, C., Cadet, P., Planchon, O., Estève, M., and Lapetite, J. M. 2003. Transport of free-living nematodes by runoff water in a SudanoSahelian area. Appl. Soil Ecol. 23:85-91.

52. Waage, J. K., Fraser, R. W., Mumford, J. D., Cook, D. C., and Wilby, A. 2004. A new agenda for biosecurity. Draft Report of the Department of Food, Environment and Rural Affairs, August. Faculty of Life Sciences, Imperial College, London.

53. VSN International 2010. GentStat for Windows, 13th ed. VSN International, Hemel Hempstead, UK.

54. Zar, J. H. 1984. Biostatistical Analysis. Prentice-Hall Inc., Englewood Cliffs, NJ. 